\title{
Comparação de Dietas Artificiais, Contendo Diferentes Fontes de Ácidos Graxos, para Criação de Elasmopalpus lignosellus (Zeller) (Lepidoptera: Pyralidae)
}

\author{
Ana M. Meneguim¹ ${ }^{1}$ José R. P. Parra ${ }^{2}$ e Marineia L. Haddad² \\ ${ }^{1}$ Instituto Agronômico do Paraná, IAPAR, Caixa postal 481, 86001-970, Londrina, PR. \\ ${ }^{2}$ Departamento Entomologia, ESALQ/USP, Caixa postal 9, 13418-900, Piracicaba, SP.
}

An. Soc. Entomol. Brasil 26(1): 35-43 (1997)

Comparison of Artificial Diets with Different Fatty Acid Sources for Rearing Elasmopalpus lignosellus (Zeller) (Lepidoptera: Pyralidae)

\begin{abstract}
Artificial diets for rearing the lesser cornstalk borer Elasmopalpus lignosellus (Zeller), containing different protein sources, and alternative fatty acid sources were compared. Results of five sucessive generations, including period of life cycle, mortality, fecundity, life span, and fertility indicated that the diet with 'Opaco' corn (Zea mays) meal, yeast and wheat (Triticum aestivum) germ, including colza (Brassica campestris) or sunflower, (Helianthus annuus) oils as a fatty acid source may be used to replace the standard diet, that contains linolenic or linoleic acids.
\end{abstract}

KEYWORDS: Insecta, life table, lesser cornstalk borer.

RESUMO - Comparou-se dietas artificiais para a criação de Elasmopalpus lignosellus (Zeller), com diferentes fontes protéicas, utilizando fontes alternativas de ácidos graxos [óleos de linhaça (Linum usitatissimun) de colza (Brassica campestris) e de girassol (Helianthus annuus)]. Os insetos foram criados por cinco gerações sucessivas, em câmaras climatizadas a $30 \pm 0,5{ }^{\circ} \mathrm{C}, 60 \pm 10 \%$ UR e fotofase de $14 \mathrm{~h}$, sendo analisada a duração e a viabilidade do período lagartaadulto; a duração dos períodos de pré-oviposição e oviposição; o número de ovos por fêmea e a longevidade; a partir destes dados foram confeccionadas tabelas de vida de fertilidade. Verificou-se que os óleos de colza e girassol podem ser utilizados como fonte de ácidos graxos, na dieta à base de milho Zea mays cv. 'Opaco', levedura de cerveja e germe-de-trigo (Triticum aestivum) nas quais E. lignosellus apresentou desempenho semelhante ao observado na dieta padrão contendo ácido linoléico.

PALAVRAS-CHAVE: Insecta, tabela de vida, lagarta elasmo.

Elasmopalpus lignosellus (Zeller), conhecida como lagarta elasmo, é considerada uma das principais pragas de diversas culturas, causando danos elevados em gramíneas, além de atacar outras plantas cultivadas (Menschoy \& Baucke 1966,Vernalha 1967,Abrahão
\& Amante 1970, Busoli et al. 1977, Gallo et al. 1988). A dificuldade de criação da lagarta elasmo, em laboratório, faz com que os estudos com este inseto dependam da sua ocorrência natural. Como tal ocorrência é função de fatores climáticos e edáficos, os insetos geral- 
mente, não se encontram disponíveis, em quantidades suficientes.

Chalfant (1975) descreveu uma técnica de criação de E. lignosellus, colocando as lagartas em recipientes contendo vermiculita sobre uma dieta artificial, em substituição à areia utilizada por Stone (1968a). Essa técnica permitiu a manutenção do inseto em laboratório por várias gerações, sendo até hoje considerada a dieta padrão para E. lignosellus. Esta dieta inclui os ácidos graxos linoléico e linolênico, que são referidos como essenciais para alguns Orthoptera (Dadd 1960), Coleoptera (Vanderzant \& Richardson 1964) e, principalmente, Lepidoptera. A deficiência destes ácidos pode resultar em pupas e .adultos deformados (Fraenkel \& Blewett 1947, Rock 1967, Levinson \& Navon 1969, Sivapalan \& Gnanapragasam 1979, Bracken 1982, Dadd 1983).

O objetivo do trabalho foi a obtenção de uma dieta artificial que possibilite a criação contínua de E. lignosellus em laboratório. Assim, foram comparadas dietas artificiais contendo diferentes fontes protéicas e componentes (especialmente ácidos graxos), adquiríveis a custo relativamente baixo, em relação à dieta normalmente utilizada em outros países, baseando-se em parâmetros biológicos e na tabela de vida de fertilidade.

\section{Material e Métodos}

O trabalho foi desenvolvido no Laboratório de Biologia, Departamento de Entomologia, ESALQ, em Piracicaba-SP, em câmara climatizada, $\mathrm{a} 30 \pm 0,5^{\circ} \mathrm{C}, 60 \pm 10 \%$ UR e fotofase de $14 \mathrm{~h}$.

As lagartas foram criadas em tubos de vidro $(2,5 \mathrm{~cm}$ x $8,5 \mathrm{~cm})$ fechados com algodão hidrófugo. Após a "inoculação" das lagartas, foi colocada sobre a dieta, preparada segundo Parra (1979), uma camada de vermiculita, previamente esterilizada em autoclave $\left(120^{\circ} \mathrm{C}, 1\right.$ atm, $20 \mathrm{~min}$ ), permitindo ao inseto a construção de abrigos. Na emergência, colocou-se dois casais/gaiola cilíndrica de PVC $(10 \mathrm{~cm}$ x $20 \mathrm{~cm})$ alimentados com solução aquosa de mel a $10 \%$.
As gaiolas foram fechadas na abertura superior e inferior com placas de Petri $(15 \mathrm{~cm}$ de diâmetro), e a base forrada com papel de filtro. Como substrato para postura, as gaiolas foram revestidas internamente com papel toalha branco. Foram comparadas seis dietas, quatro baseadas em Chalfant (1975) usada como padrão e duas baseadas em Mihsfeldt (1985) (Tabela 1). Na dieta de Chalfant (1975) modificada (dieta C) substituiu-se o ácido linoléico (1,5 $\mathrm{ml}$ ) por óleos vegetais de linhaça (Linum usitatissimum), de colza (Brassica campesffis) e de girassol (Helianthus annuus)], que contêm diferentes percentagens de ácidos graxos saturados e poliinsaturados, na quantidade de $2 \mathrm{ml}$. Na dieta de Mihsfeldt (1985) modificada (dieta $\mathrm{M}$ ) foram adicionados $2 \mathrm{ml}$ dos óleos de colza e de girassol.

Os insetos foram criados por cinco gerações sucessivas, sendo feitas avaliações biológicas nas duas primeiras com a dieta $\mathrm{C}$ (na $2^{a}$ geração, aumentou-se em $50 \%$ a concentração de óleos nas dietas) e, posteriormente, na quinta geração, para verificar a qualidade do inseto ao longo das gerações. Nesta quinta geração, foi comparado o desenvolvimento do inseto nas dietas $\mathrm{C}$ e M, eliminando-se o óleo de linhaça, mantendo-se a concentração dos ácidos graxos da $1^{a}$ geração de laboratório. Para avaliar o desenvolvimento biológico foi utilizado até 40 tubos/tratamento na $1^{a}$ geração, 120 na $2^{\text {a }}$ geração (5 lagartas/tubo) e até 240 na $5^{\text {a }}$ geração (2 lagartas/tubo). A reprodução foi avaliada utilizando-se no máximo 10,11 e 21 gaiolas/tratamento na $1^{\mathrm{a}}, 2^{\mathrm{a}}$ e $3^{\mathrm{a}}$ geração, respectivamente.

Foram determinados a duração e a viabilidade do período lagarta-adulto, duração do período de pré-oviposição e oviposição, número de ovos por fêmea e a respectiva longevidade de machos e fêmeas. A sobrevivência foi estimada pelo modelo de Weibull (Sgrillo 1982). A viabilidade do período foi determinada calculando-se a percentagem de adultos emergidos em relação ao número total de lagartas "inoculadas". Para a determinação do período lagarta-adulto foram feitas observa- 
Tabela 1. Composição da dieta artificial padrão (Chalfant 1975) e da dieta artificial de Mihsfeldt (1985), para Elasmopalpus lignoselus.

\begin{tabular}{lcc}
\hline & \multicolumn{2}{c}{ Quantidade (ml ou g) } \\
\cline { 2 - 3 } Componente & Chalfant (1975) & Mihsfeldt (1985) \\
\hline Líquido & 1,5 & \\
Ácido linoléico' & 375,0 & 400,00 \\
Água destilada & 0,7 & \\
Solução vitamínica ${ }^{2}$ & & \\
& & \\
Sólido & 2,0 & 0,50 \\
Ácido ascórbico & 0,6 & 10,00 \\
Ácido sórbico & & \\
Ácido benzóico & 7,0 & 56,00 \\
Ágar & 0,022 & 14,00 \\
Aureomecina & & 15,00 \\
Milho 'Opaco' (farinha) & 60,0 & 0,40 \\
Feijão 'Carioca' & 29,5 & \\
Germe-de-trigo & 19,0 & \\
Levedura de cerveja & 1,10 & \\
Metil parahidroxibenzoato (nipagin) & & \\
\end{tabular}

${ }^{1}$ Substituiu-se o ácido linolênico pelo ácido linoléico da dieta original.

${ }^{2}$ Composição da solução vitamínica (Parra 1979).

ções diárias quantificando-se o número de insetos emergidos em cada dieta. O desempenho reprodutivo foi avaliado utilizando-se números variáveis de casais (10 a 42) de diferentes dietas e gerações. Os dados biológicos de E. lignosellus, da $5^{\text {a }}$ geração de laboratório, foram utilizados para elaboração da tabela de vida de fertilidade para cada dieta artificial, conforme Silveira Neto et al. (1976). O delineamento experimental, foi inteiramente casualizado. $\mathrm{Na}$ análise estatística os dados de viabilidade foram transformados por arco seno $\sqrt{\mathrm{x} / 100}$ e o número de ovos/gaiola por $\sqrt{\mathrm{x}+0,5}$. A comparação entre as médias dos tratamentos foi realizada através do teste de Tukey $(\mathrm{P}<0.05)$.

\section{Resultados e Discussão}

Não houve diferença na duração e viabilidade do período lagarta-adulto de E. ligno- sellus mantida na dieta $\mathrm{C}$ com modificações, na $1^{\text {a }}$ geração do laboratório (Tabela 2). Os valores da duração lagarta-adulto observados foram superiores aos obtidos por Chalfant (1975) (média de 25 dias), que utilizou ácido linolênico como fonte de ácido graxo e por Stone (1968a) (média do ciclo de vida de 26 dias) utilizando dieta artificial com base protéica de germe-de-trigo e caseína, sem o fornecimento de ácido graxo poliinsaturado. Com relação à viabilidade do período (lagarta-adulto), os óleos utilizados (linhaça, colza e girassol) foram adequados para suprir as exigências nutricionais de E. lignosellus, pois os valores de viabilidade (46 a 50\%) estiveram próximos daqueles relatados por Chalfant (1975).

O aumento de $50 \%$ na concentração de óleo nas dietas, testadas na segunda geração, não apresentou efeito favorável, desde que houve um alongamento do período lagarta- 
Tabela 2. Duração e viabilidade $(\mathrm{X} \pm \mathrm{EP})$ do período lagarta-adulto de Elasmopalpus lignosellus em dietas contendo diferentes fontes alternativas ao ácido graxo, em três gerações de laboratório.

\begin{tabular}{|c|c|c|c|c|c|c|c|}
\hline \multirow{2}{*}{$\begin{array}{l}\text { Dieta } \\
\text { original }\end{array}$} & \multirow{2}{*}{$\begin{array}{l}\text { Fonte de ácido } \\
1^{1} \text { graxo }\end{array}$} & \multicolumn{3}{|c|}{ Duração (dias) ${ }^{2}$} & \multicolumn{3}{|c|}{ Viabilidade $(\%)^{2}$} \\
\hline & & F1 & $\mathrm{F} 2$ & F5 & F1 & $\mathrm{F} 2$ & F5 \\
\hline $\mathrm{C}$ & Ácido linoléico & $32,9 \pm 0,61 \mathrm{a}$ & $40,7 \pm 0,55 \mathrm{a}$ & $43,2 \pm 1,20 \mathrm{ab}$ & $49,0 \pm 0,21 \mathrm{a}$ & $22,7 \pm 0,01$ a & $44,3 \pm 0,04 \mathrm{~b}$ \\
\hline $\mathrm{C}$ & Óleo de linhaça & $34,4 \pm 0,59 a$ & $41,3 \pm 0,54 \mathrm{a}$ & - & $41,2 \pm 0,21 \mathrm{a}$ & $19,2 \pm 0,01 \mathrm{~b}$ & - \\
\hline $\mathrm{C}$ & Óleo de colza & $32,7 \pm 0,61 \mathrm{a}$ & $41,6 \pm 0,52 \mathrm{a}$ & $46,9 \pm 1,20 \mathrm{a}$ & $46,0 \pm 0,21 \mathrm{a}$ & $20,9 \pm 0,01 \mathrm{ab}$ & $30,2 \pm 0,04 \mathrm{c}$ \\
\hline $\mathrm{C}$ & Óleo de girassol & $32,7 \pm 0,64 \mathrm{a}$ & $40,9 \pm 0,57 \mathrm{a}$ & $47,4 \pm 1,20 \mathrm{a}$ & $42,0 \pm 0,21 \mathrm{a}$ & $23,7 \pm 0,01 \mathrm{a}$ & $30,4 \pm 0,04 \mathrm{c}$ \\
\hline M & Óleo de colza & - & - & $41,7 \pm 1,20 \mathrm{~b}$ & - & & $61,6 \pm 0,04 \mathrm{a}$ \\
\hline M & Óleo de girassol & - & - & $43,8 \pm 1,23 \mathrm{~b}$ & - & & $50,4 \pm 0,04 \mathrm{~b}$ \\
\hline
\end{tabular}

${ }^{1} \mathrm{C}=$ dieta à base de feijão, levedura de cerveja e germe-de-trigo, e $\mathrm{M}=$ dieta à base de milho 'Opaco', levedura de cerveja e germe-de-trigo.

${ }^{2}$ Médias seguidas da mesma letra não diferem entre si, nas colunas, pelo teste de Tukey $(\mathrm{P} \leq$ $0,05)$.

adulto em torno de $20 \%$. Embora as diversas fontes de ácidos graxos tenham afetado igualmente a duração do período lagarta-adulto, com relação à viabilidade, houve diferenças, sendo que o aumento da concentração dos óleos de colza e linhaça promoveram menor viabilidade (Tabela 2). Chippendale \& Reddy (1972) também observaram que o aumento da quantidade de óleos não favoreceu o crescimento larval de Diatraea grandiosella Dyar.

Segundo Dadd \& Kleinjan (1979) o alto grau de insaturação dessas substâncias favorece a oxidação, o que pode não somente diminuir rapidamente a quantidade de ácidos graxos essenciais na dieta, como também resultar em produtos mais tóxicos do que inativos, tomando o alimento inadequado ao consumo normal. Por outro lado, a redução da viabilidade, na segunda geração pode ainda ser atribuída ao processo de adaptação do inseto às condições de criação desde que, na dieta C sem o aumento da quantidade de ácido linoléico também houve diminuição da viabilidade (Tabela 2). O inseto sofre um processo de adaptação em laboratório, que só atinge a sua plenitude em tomo da $5^{\mathrm{a}}$ a $7^{\mathrm{a}}$ gerações, em condições ótimas (Boller \& Chambers 1977).
Como o aumento da quantidade dos óleos, na $2^{\text {a }}$ geração, não surtiu resultados positivos quanto à duração e viabilidade de E. lignosellus, optou-se pela manutenção das quantidades utilizadas na dieta preparada na $\mathrm{l}^{\mathrm{a}}$ geração, para os estudos das gerações posteriores. $\mathrm{Na} 5^{\text {a }}$ geração, a viabilidade proporcionada pela dieta M com óleo de colza foi superior às obtidas nas demais. Esta dieta também proporcionou um dos menores períodos de desenvolvimento, o qual foi semelhante à dieta padrão.

Em todas as dietas estudadas na $5^{\text {a }}$ geração, a longevidade dos adultos foi superior àquela observada por Chalfant (1975), que obteve duração de cinco dias para fêmeas e de oito dias para machos. Também foi constatada a tendência dos machos viverem mais que as fêmeas, sendo que houve casos em que a longevidade média dos machos atingiu 42,1 dias e a das fêmeas 27,0 dias. A longevidade dos adultos provenientes das diferentes dietas obedeceu à distribuição de Weibull (Fig. 1) permitindo, assim, a sua estimativa em condições de laboratório, para previsão de produção deste inseto. Com relação a este parâmetro, todas as dietas mostraram-se adequadas, uma vez que produziram adultos longevos. 

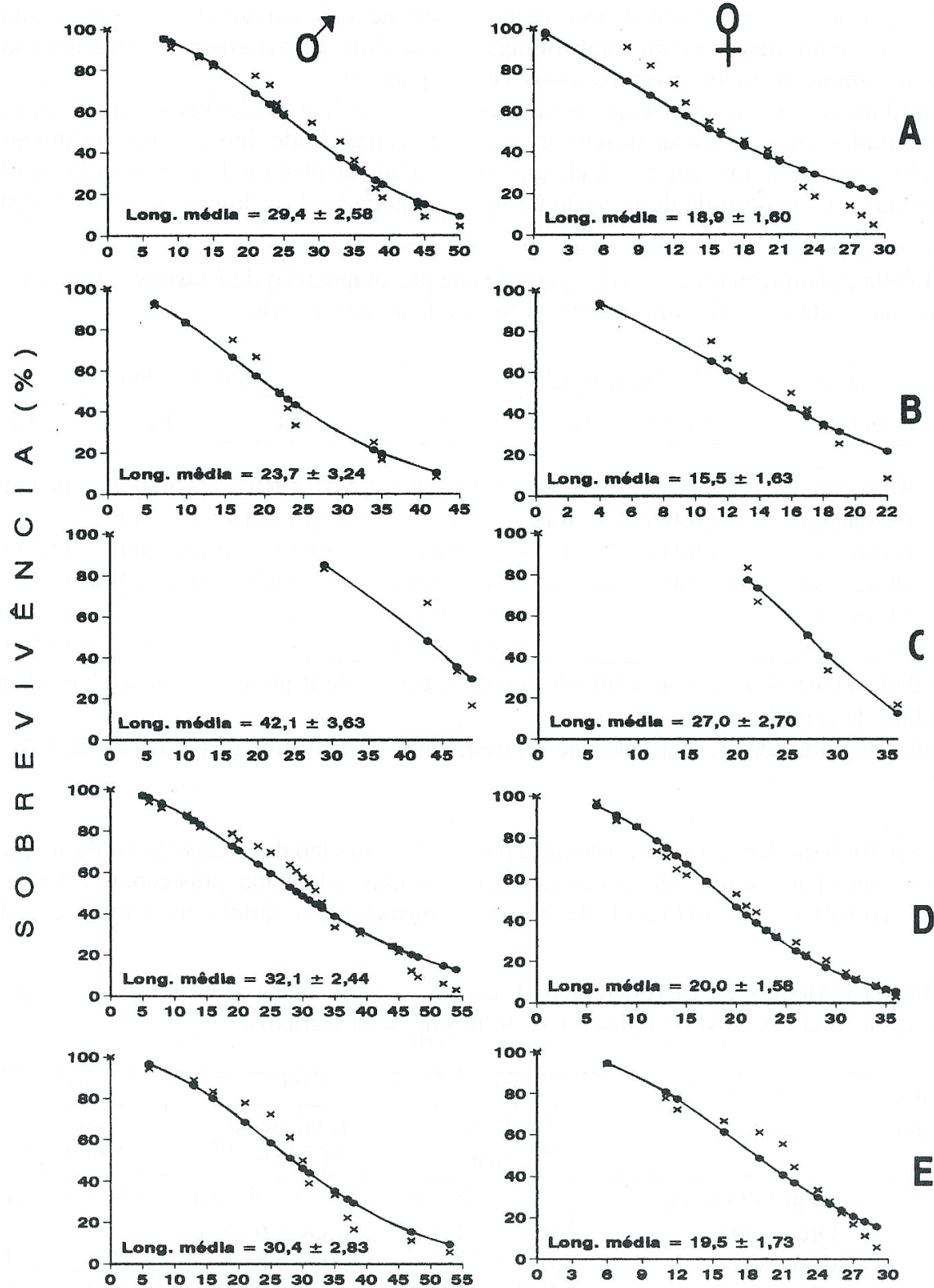

$$
\text { LONGEVIDADE (DIAS) }
$$

Figura 1. Sobrevivência (\%) e longevidade (X $\pm \mathrm{EP})$ de Elasmopalpus lignosellus criados na dieta C com ácido linoléico (A), óleo de colza (B), e óleo de girassol (C) e na dieta M com [oleo de colza (D) e de girassol (E). Valores observados pela equação de Weibull. 
Os períodos de pré-oviposição e oviposição não foram afetados com a substituição do ácido linoléico pelos diversos óleos vegetais (Tabela 3). Constatou-se que os valores apresentados pelas fêmeas desenvolvidas nos alimentos testados, em geral, chegaram a ser mais que o dobro da duração do perío- do de oviposição de fêmeas criadas por Chalfant (1975) na dieta C com ácido linolênico (padrão).

A utilização de óleos vegetais em substituição ao ácido linoléico não influiu na capacidade de postura de E. lignosellus na $1^{\text {a }}$ e na $2^{\mathrm{a}}$ geração. O número de ovos/fêmea da $5^{\mathrm{a}}$

Tabela 3. Duração $(\mathrm{X} \pm \mathrm{EP})$ dos períodos de pré-oviposição de Elasmopalpus lignosellus criado nas dietas $\mathrm{C}$ e $\mathrm{M}$, com diferentes fontes de ácidos graxos.

\begin{tabular}{|c|c|c|c|c|c|c|c|}
\hline \multirow{2}{*}{$\begin{array}{l}\text { Dieta } \\
\text { original }\end{array}$} & \multirow{2}{*}{$\begin{array}{l}\text { Fonte de ácido } \\
\text { l' graxo }\end{array}$} & \multicolumn{3}{|c|}{ Duração $(\text { dias })^{2}$} & \multicolumn{3}{|c|}{ Viabilidade $(\%)^{2}$} \\
\hline & & $\mathrm{F} 1$ & $\mathrm{~F} 2$ & F5 & $\mathrm{F} 1$ & $\mathrm{~F} 2$ & F5 \\
\hline $\mathrm{C}$ & Ácido linoléico & $5,2 \pm 0,44 \mathrm{a}$ & $4,9 \pm 0,46 a$ & $4,8 \pm 0,46 a$ & $18,1 \pm 0,40 \mathrm{a}$ & $15,2 \pm 0,38 \mathrm{a}$ & $19,7 \pm 0,40 a$ \\
\hline $\mathrm{C}$ & Óleo linhaça & $5,3 \pm 0,41$ a & $4,4 \pm 0,44 \mathrm{a}$ & - & $19,8 \pm 0,31 \mathrm{a}$ & $11,5 \pm 0,30 \mathrm{a}$ & - \\
\hline $\mathrm{C}$ & Óleo colza & $7,2 \pm 0,44 a$ & $2,7 \pm 1,73 \mathrm{a}$ & $7,2 \pm 0,42 a$ & $15,3 \pm 0,37 \mathrm{a}$ & $15,0 \pm 0,10 \mathrm{a}$ & $14,8 \pm 0,31 \mathrm{a}$ \\
\hline $\mathrm{C}$ & Óleo girassol & $4,2 \pm 0,45 \mathrm{a}$ & $4,4 \pm 0,40 a$ & $4,3 \pm 0,34 \mathrm{a}$ & $16,4 \pm 0,40 \mathrm{a}$ & $16,6 \pm 0,26 \mathrm{a}$ & $19,3 \pm 0,22 a$ \\
\hline M & Óleo colza & - & - & $4,7 \pm 0,47 a$ & - & - & $19,5 \pm 0,43 a$ \\
\hline M & Óleo girassol & - & - & $4,1 \pm 0,46 a$ & - & - & $14.7 \pm 0.40 \mathrm{a}$ \\
\hline
\end{tabular}

${ }^{1} \mathrm{C}=$ dieta à base de feijão, levedura de cerveja e germe-de-trigo, e $\mathrm{M}=$ dieta à base de milho, levedura de cerveja e germe-de-trigo.

Médias seguidas da mesma letra não diferem entre si, nas colunas, pelo teste de Tukey $(\mathrm{P} \leq$ $0,05)$.

geração, foi semelhante ao obtido na dieta padrão, exceto para fêmeas desenvolvidas na dieta $\mathrm{C}$ com óleo de colza (Tabela 4). A dieta
M, com óleo de colza e de girassol, mostrouse mais adequada, pois cerca de $15 \%$ das fêmeas foram inférteis, enquanto que na dieta $\mathrm{C}$

Tabela 4. Média (X \pm EP) do número de ovos colocados/fêmea de Elasmopalpus lignosellus criadas nas dietas $\mathrm{C}$ e $\mathrm{M}$ com diferentes fontes de ácidos graxos.

\begin{tabular}{|c|c|c|c|c|}
\hline \multirow{2}{*}{$\begin{array}{l}\text { Dieta } \\
\text { orignal }^{1}\end{array}$} & \multirow{2}{*}{$\begin{array}{c}\text { Fonte de ácido } \\
\text { graxo }\end{array}$} & F1 & $\mathrm{F} 2$ & F5 \\
\hline & & $\begin{array}{l}\text { Total ovos/ } \\
2 \text { fêmeas }{ }^{2,3}\end{array}$ & $\begin{array}{l}\text { Total ovos/ } \\
2 \text { fêmeas } 2.3\end{array}$ & $\begin{array}{l}\text { Total ovos/ } \\
2 \text { fêmeas }{ }^{2,3}\end{array}$ \\
\hline $\mathrm{C}$ & Ácido linoléico & $309,0 \pm 68,8 \mathrm{a}$ & $208,5 \pm 43,9 a$ & $314,4 \pm 36,1 \mathrm{a}$ \\
\hline $\mathrm{C}$ & Óleo linhaça & $346,2 \pm 84,4$ a & $203,8 \pm 67,8 \mathrm{a}$ & - \\
\hline $\mathrm{C}$ & Óleo colza & $202,7 \pm 77,4 \mathrm{a}$ & $239,5 \pm 81,5 \mathrm{a}$ & $115,0 \pm 46,4 b$ \\
\hline $\mathrm{C}$ & Óleo girassol & $346,2 \pm 74,2 \mathrm{a}$ & $467,4 \pm 128,8 \mathrm{a}$ & $356,2 \pm 153,8 \mathrm{a}$ \\
\hline M & Óleo de colza & & & $324,3 \pm 35,1 \mathrm{a}$ \\
\hline M & Óleo girassol & & & $239,9 \pm 50,5 a b$ \\
\hline
\end{tabular}

${ }^{1} \mathrm{C}=$ dieta à base de feijão, levedura de cerveja e germe-de-trigo, e $\mathrm{M}=$ dieta à base de milho 'Opaco', levedura de cerveja e germe-de-trigo.

${ }^{2}$ Médias seguidas da mesma letra não diferem entre si, nas colunas, pelo teste de Tukey $(\mathrm{P} \leq$ $0,05)$.

${ }^{3}$ Número de ovos/gaiola com fêmeas que realizaram postura. 
variou de 24 a $27 \%$. O ritmo de postura dos insetos criados na dieta $\mathrm{M}$ foi semelhante aquele obtido por Chalfant (1975), ou seja, cerca de $40 \%$ dos ovos foram colocados nos primeiros cinco dias da vida de E. lignosellus. O número de ovos/fêmea chegou a ser até quatro vezes maior que o valor mencionado por Chalfant (1975), de 47 ovos e por Nakayama (1980), de 54 ovos, para fêmeas de- senvolvidas em dieta artificial (dieta $\mathrm{C}$ com ácido linolênico) e natural (plantas de trigo Triticum aestivum), respectivamente. Embora o espaço da gaiola fornecido por inseto(192 $\mathrm{cm}^{3}$ ), estivesse dentro do ótimo relato por Stone (1968b), não se conseguiu postura com apenas um casal. Dessa forma, a avaliação do desempenho reprodutivo foi realizada com duas fêmeas/gaiola, população mínima em que se

Tabela 5. Taxa líquida de reprodução (Ro), duração médias de cada geração (T), capacidade inata de aumentar em número (rm), razão finita de aumento $(\lambda)$ de Elasmopalpus lignosellus, mantida em cinco dietas artificiais. Fases imaturas, $30 \pm 0,5{ }^{\circ} \mathrm{C} ; 60 \pm 10 \% \mathrm{UR}$; fotofase: $14 \mathrm{~h}$.

\begin{tabular}{lcccccc}
\hline $\begin{array}{l}\text { Dieta } \\
\text { original }^{1}\end{array}$ & $\begin{array}{c}\text { Fonte de ácido } \\
\text { graxo }\end{array}$ & Ro & T(dias) & rm & $\lambda$ & $\begin{array}{r}N^{\circ} \text { de casais } \\
\text { observados }\end{array}$ \\
\hline C & Ácido linoléico & 16,01 & 63,82 & 0,0435 & 1,0444 & 24 \\
$\mathrm{C}$ & Óleo colza & 4,77 & 74,31 & 0,0210 & 1,0212 & 14 \\
$\mathrm{C}$ & Óleo girassol & 10,56 & 64,96 & 0,0314 & 1,0319 & 14 \\
$\mathrm{M}$ & Óleo colza & 25,28 & 69,53 & 0,0464 & 1,0475 & 42 \\
$\mathrm{M}$ & Óleo girassol & 17,10 & 67,42 & 0,0421 & 1,0430 & 26 \\
\hline
\end{tabular}

${ }^{1} \mathrm{C}=$ dieta à base de feijão, levedura de cerveja e germe-de-trigo e $\mathrm{M}=$ dieta à base de milho 'Opaco', levedura de cerveja e germe-de-trigo.

obteve postura de E. lignosellus. J. R. Calvo citado por Stone (1968b) somente observou acasalamento com cinco casais $/ 30 \mathrm{~cm}^{3}$. O maior número de ovos encontrado é uma indicação favorável da adequação do substrato alimentar utilizado.

Analisando-se a tabela de vida de fertilidade (Tabela 5), verifica-se que a dieta M (com óleo de colza ou girassol) foi superior à dieta padrão, pois baseando-se na taxa líquida de reprodução (Ro), tais dietas deram origem à populações com capacidade de aumento de 25,3 e 17,1 vezes, respectivamente, a cada geração, em relação às 16,0 vezes de aumento proporcionado pela dieta padrão. A razão finita do aumento $(\lambda)$ e a capacidade inata de aumentar em número $(\mathrm{rm})$ também foram superiores na dieta $\mathrm{M}$ com óleo de colza, com resultados comparáveis aos obtidos na dieta padrão, inclusive com relação à duração do período $(\mathrm{T})$. É provável que a característica do milho 'Opaco', ou seja, mais rico em lisina e triptofano em relação a outros híbridos ou variedades de milho (Mihsfeldt 1985), tenha sido importante nesta adequação nutricional da referida dieta. Sugerem-se estudos para avaliar o comportamento do inseto em dietas compostas de outros híbridos de milho.

Considerando-se os resultados obtidos, a dieta M, à base de milho' Opaco', germe-de- 
trigo e levedura de cerveja, poderá ser utilizada para criação contínua de E. lignosellus, substituindo-se o ácido linoléico pelos óleos de colza e girassol, fonte de ácidos graxos de fácil aquisição no mercado, se comparados ao ácido linoléico. O alongamento do período lagarta-adulto na geração F5, pode ser devido aos ajustes de adequação nutricional realizados. É possível que coletando-se insetos de campo, após cinco a sete gerações na dieta $\mathrm{M}$ proposta, ocorra uma adaptação às condições de laboratório, fato bastante comum em Pyralidae (P. Singh, comunicação pessoal).

\section{Literatura Citada}

Abrahão, J. \& E. Amante 1970. Fungos causadores de tombamento de mudas de algodoeiro no ano agrícola 1969 - 70. Biológico 36:24-2 5.

Boller, E., F. \& D.L. Chambers 1977. Quality aspects of mass-reared insects, p.219-235. In R.L. Ridgway \& S.B. Vinson, (ed.), Biological control by augmentation of natural enemies. New York, Plenum, 450p.

Bracken, G.K. 1982. The bertha armyworm, Mamestra configurata (Lepidoptera: Noctuidae). Effects of dietary linoleic acid on pupal syndrome, wing syndrome, survival, and pupal fat composition. Can. Entomol. 114:567-573.

Busoli,A.C., F. M. Lara, D. Nunes Junior \& M. Guidi 1977. Preferências de Elasmopalpus lignosellus (Zeller 1848) (Lepidoptera: Phycitidae). An. Soc. Entomol. Brasil 6:73-79.

Chalfant, R.B. 1975. A simplified technique for rearing the lesser cornstalk borer (Lepidoptera: Phycitidae). J. Georgia Entomol. Soc. 10:33-37.
Chippendale, G.M. \& G.P.V. Reddy 1972. Polyunsaturated fatty acid and sterol requirements of the southwesterm corn borer, Diatraea grandiosela. J. Insect Physiol.18:305-316.

Dadd, R.H. 1960. The nutritional requirements of locusts. Development of synthetic diets and lipid requirements. J. Insect Physiol. 4:319-347.

Dadd, R.H. 1983. Long-chain polyenoics and the essential dietary fatty acid requirement of the waxmoth, Galleria mellonella. J. Insect Physiol. 29: 779-786.

Dadd, R.H. \& J.E. Kleinjan 1979. Essential fatty acid for the mosquito Culex pipiens: arachidonic acid. J. Insect Physiol. 25:495502.

Fraenkel, G. \& M. Blewett 1947. Linoleic acid and arachidonic acid in the metabolism of two insects, Ephestia kuehniella (Lep.) and Tenebrio molitor (Col.). J. Biochem. 41:475-478.

Gallo, D., O. Nakano, S. Silveira Neto, R.P.L. Carvalho, G.C. Batista, E. Berti Filho, J.R.P. Parra, A.R. Zucchi, S.B. Alves, J.D.Vendramim 1988. Manual de entomologia agrícola 2. ed.. São Paulo, Agronómica Ceres, 649p.

Levinson, H.Z. \& A. Navon 1969. Ascorbic acid and unsaturated fatty acids in the nutrition of the Egyptian cotton leafworm, Prodenia litura. J. Insect Physiol. 15:491-495.

Menschoy,A.B. \& O. Baucke 1966. Segunda relação das pragas das plantas cultivadas no Rio Grande do Sul. Pesq. Agropec. Bras. 1:17-46. 
Mihsfeldt, L.H. 1985. Comparação de dietas artificiais para criação de Diatraea saccharalis (Fabricius 1794) (LepidopteraPyralidae). Tese de mestrado, ESALQ/ USP, Piracicaba, 120 p.

Nakayama, K. 1980. Biologia e controle de Elasmopalpus lignosellus (Zeller 1848) (Lepidoptera-Pyralidae) em trigo. Tese de mestrado, ESALQ/USP, Piracicaba, 65p.

Parra, J.R.P. 1979. Biologia dos Insetos. Piracicaba, ESALQ/USP, 383 p.

Rock, C.G. 1967. Aseptic rearing of the cloding moth on synthetic diets: ascorbic acid and fatty acid requirements. J. Econ. Entomol. 60:1002-1005.

Sgrillo, R.B. 1982. A distribuição de Weibull como modelo de sobrevivência de insetos. Ecossistema 7: 10-13.

Silveira Neto, S., O. Nakano, D. Barbin, N.A. Villa Nova 1976. Manual de ecologia dos insetos. São Paulo, Agronômica Ceres, 419p.

Sivapalan, P. \& N.C. Gnanapragasam 1979.

The influence of linoleic acid and linolenic acid on adult moth emergence of Homona caffearia from meridic diets in vitro. $\mathrm{J}$. Insect Physiol. 25: 393-398.

Stone, K.J. 1968a. Reproductive biology of lesser cornstalk borer. I. Rearing technique. J. Econ.Entomol. 61:1712-1714.

Stone, K. J. 1968b. Reproductive biology of lesser cornstalk borer. II. Cage condition and sex ratios for mating. J. Econ. Entomol.61:1715-1716.

Vanderzant, E.S. \& C.D. Richardson 1964. Nutrition of the adult boll weevil: lipid requirements. J. Insect Physiol. 10: 267272.

Vernalha, M.M. 1967. Uma nova praga de Araucaria angustifolia (Bert.) O. Kuntze, no Estado do Paraná - Elasmopalpus lignosellus (Zeller 1848) (LepidopteraPhycitidae). Rev. Esc. Sup. Agron. Veter. Univ. Fed. Paraná 3:141 -142.

Recebido em 07/06/96. Aceito em 06/01/97. 